\title{
Avaliação da percepção de valor em Empreendimentos Habitacionais de Interesse Social: perspectivas de técnicos e de usuários
}

\author{
Assessment of perceived value in social housing: technical \\ developers' and users' perspectives
}

\section{Deyvid Aléx de Bitencourt Monteiro Luciana Inês Gomes Miron Jeferson Shin-Iti Shigaki Marcia Elisa Soares Echeveste}

\section{Resumo}

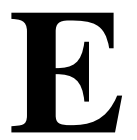

ste artigo propõe-se uma análise que combina as percepções de valor das esferas de desenvolvimento (técnicos da Prefeitura Municipal de Porto Alegre) e ocupação (usuários) de empreendimentos habitacionais utilizando o mapeamento hierárquico de valor. A estratégia de pesquisa adotada é a Constructive Research. A população-alvo "usuários" faz parte do EHIS A.J. Renner pertencente ao Programa Integrado Entrada da Cidade. O processo de pesquisa envolveu a construção de um questionário, planejamento amostral, coleta e análise de dados utilizando técnicas estatísticas descritivas e laddering cujo resultado é representado pelo mapeamento hierárquico de valor (MHV). Dentre os principais resultados, a unidade habitacional representou a maior divergência entre as percepções dos técnicos e dos usuários. Já o empreendimento representou uma boa convergência entre as percepções de ambos. Ainda, o MHV permitiu explorar quais benefícios estão sendo atingidos pelo programa, além da relação desses benefícios com a satisfação e permanência dos usuários no EHIS. A principal contribuição desta pesquisa está na identificação dos níveis mais abstratos presentes na percepção dos usuários, insuficientemente compreendidos pelos técnicos ou explicitados pelos programas habitacionais brasileiros.

Palavras-chaves: Empreendimentos Habitacionais de Interesse Social (EHIS). Avaliação de percepção de valor. Hierarquia de valor percebido.

Deyvid Aléx de Bitencourt Monteiro

Universidade Federal do Rio Grande do Sul Porto Alegre - RS - Brasil

Luciana Inês Gomes Miron Universidade Federal do Rio Grande Porto Alegre - RS - Brasil

Jeferson Shin-Iti Shigaki Universidade Federal do Rio Grande do Sul Porto Alegre - RS - Brasil

Marcia Elisa Soares Echeveste Universidade Federal do Rio Grande

Porto Alegre - RS - Brasil

Recebido em 30/03/15 Aceito em 18/08/15

\section{Abstract}

This article aims to propose an analysis that combines the value perceptions of development levels (technicians from the city council of Porto Alegre) and occupation (users) of housing projects using a hierarchical value mapping.

The research strategy adopted is Constructive Research. The target population 'users' is part of SHP A.J. Renner belonging to the Programa Integrado Entrada da Cidade. The research process involved the elaboration of a questionnaire, a sample design, data collection and data analysis using descriptive statistics techniques and laddering, whose result is represented by the value hierarchy mapping $(M H V)$. Among the main results, the housing project unit accounted for the largest discrepancy between the perceptions of technical developers and users. The housing project, in turn, showed good convergence between the perceptions of both. Besides, the MHV allowed exploring which benefits are being achieved by the program, as well as the relations of those benefits with the satisfaction and retention of users in SHP. The main contribution of this study is to identify the most abstract levels present in the perception of users that are poorly understood by technical developers or insufficiently clear in Brazilian housing programs.

Keywords: Social housing. Perceived value assessment. Perceived value hierarchy. 


\section{Introdução}

Segundo Woodruff e Gardial (1996), pesquisadores da área de marketing, as avaliações tradicionais de produtos tendem a focar na percepção dos usuários sobre os atributos físicos do produto, o que resulta em um entendimento do valor percebido superficial e pouco claro. Problema similar ocorre no contexto habitacional quando as avaliações pós-ocupacionais tendem a enfatizar apenas os atributos do produto habitação em vez de características mais abstratas presentes na percepção dos usuários, influenciadas por componentes emocionais, como os valores pessoais ou objetivos esperados desses indivíduos em relação à habitação (BONATTO, 2010; BRITO; FORMOSO; ROCHA, 2012). Diante disso, algumas pesquisas vêm demonstrando a importância de que esses níveis mais abstratos sejam considerados nas avaliações tanto para a percepção dos usuários quanto para a dos técnicos responsáveis pelo desenvolvimento de empreendimentos habitacionais (MIRON, 2008; BONATTO, 2010; TILLMANN et al., 2011).

Nesse sentido, as pesquisas de Coolen e Hoekstra (2001), Jusan (2010) e Zinas (2013a, 2013b) têm apresentado contribuições para a compreensão e mensuração do comportamento de escolha e preferências dos usuários em relação ao produto habitação. De acordo com Zinas, Bin e Jusan (2010), o comportamento de escolha dos usuários em relação ao produto habitação geralmente está associado a esses fatores abstratos e emocionais, os quais podem ser revelados por meio de estudos que envolvam o valor percebido. Tais pesquisas têm investigado o uso do modelo Means-end Chain (Cadeia de Meios-fim), desenvolvido por Gutman (1982) a partir de suas aplicações nos campos da psicologia e marketing.

Considerando o contexto dos pesquisadores da área de marketing, do ponto de vista dos usuários, produtos e serviços são meios para um fim, e, portanto, a entrega de valor deveria ser baseada em uma compreensão mais precisa do que é percebido como valor pelos usuários (WOODRUFF; GARDIAL, 1996). Para Woodruff e Gardial (1996), o julgamento de valor percebido envolve relações complexas entre o produto que é oferecido (bens e serviços), com as consequências resultantes na situação de uso desse produto, e os objetivos que os usuários desejam alcançar por meio desse produto (os quais estão associados aos valores pessoais desses usuários). Tais relações podem ser desdobradas e representadas em uma estrutura conceitual de valor percebido, a qual é fundamentada no modelo Cadeia de Meios-fim (GUTMAN, 1982).
O modelo de Cadeia de Meios-fim tem como principais objetivos identificar os valores dos usuários e o potencial que determinados produtos (meios) têm para atender a esses valores (fins) por meio de seus atributos (GUTMAN, 1982). Para Khalifa (2004), a estrutura teórica desse modelo preenche uma lacuna na literatura de valor percebido ao esclarecer por que os usuários conferem diferentes pesos em suas avaliações de alternativas de produtos. Woodruff e Gardial (1996) argumentam que o modelo de Cadeia de Meios-fim pode ser considerado em diferentes momentos da relação do usuário como o produto, por meio do valor percebido antes da aquisição (valor desejado), assim como do valor percebido durante o uso de um produto (valor recebido).

Entre a principal contribuição do uso do modelo de Cadeia de Meios-fim está a possibilidade de entender como significados concretos do produto ganham relevância para os usuários por meio das relações com significados mais abstratos presentes em sua percepção (REYNOLDS; GENGLER; HOWARD, 1995). Segundo Reynolds e Olson (2008), esse modelo atua conectando os atributos concretos de um produto aos valores pessoais dos usuários por meio de uma cadeia cognitiva que possui seis níveis de abstração:
(a) atributos concretos;
(b) abstratos;
(c) consequências funcionais;
(d) psicossociais;
(e) valores instrumentais; e
(f) terminais.

Diante do potencial de contribuição desse modelo para a compreensão e estruturação dos níveis mais abstratos presentes na percepção dos usuários, o modelo de Cadeia de Meios-fim tem sido utilizado como fundamentação teórica para algumas pesquisas com foco na avaliação de empreendimentos habitacionais de interesse social (EHIS) brasileiros (MIRON, 2008; MIRON; FORMOSO, 2009; BONATTO, 2010). Tais pesquisas têm apresentado contribuições para o entendimento do valor percebido pelos beneficiários dessa tipologia de produto ao explorar por meio do modelo de Cadeia de Meiosfim a percepção de valor dos técnicos (de prefeituras e de instituição de financiamento habitacional) durante o desenvolvimento dos empreendimentos habitacionais (valor desejado) e a percepção dos usuários após sua ocupação (valor recebido).

38 Monteiro, D. A. B.; Miron, L. I. G.; Shigaki, J. S.; Echeveste, M. E. S. 
Em contraponto, a análise dessas pesquisas também permitiu evidenciar algumas limitações relacionadas ao método, sobretudo dos instrumentos de coleta e análise de dados empregados nesses estudos, os quais resultaram em um entendimento do valor percebido pelo usuário ainda limitado aos níveis de atributos e consequências de uso do produto habitação. As pesquisas mencionadas utilizaram fundamentação teórica baseada na hierarquia de valor percebido e no modelo de Cadeia de Meios-fim. Contudo, as mesmas pesquisas utilizaram métodos tradicionalmente empregados em avaliações (questionários e técnicas estatísticas), o que acabou resultando na dificuldade de explicitação dos níveis mais abstratos da hierarquia, como os objetivos e valores pessoais dos usuários. Além disso, a análise dessas pesquisas evidenciou que os técnicos entrevistados demonstravam ter uma visão um tanto genérica e limitada aos objetivos dos programas habitacionais brasileiros.

Silva (2014) identificou que tanto os conceitos como as técnicas de mensuração tradicionalmente utilizados nas avaliações pós-ocupação tendem a estar focados nos níveis de atributos e consequências. A partir disso, a presente pesquisa parte do pressuposto de que técnicas de pesquisa mais adequadas para a hierarquia de valor percebido poderiam facilitar a coleta, análise e disseminação de resultados. Entre as técnicas de pesquisa existentes, a laddering tem sido amplamente aplicada em pesquisas do ambiente construído (COOLEN; HOEKSTRA, 2001; ZINAS; JUSAN, 2012; BRITO; FORMOSO; ROCHA, 2012; ZINAS, 2013b). Ao comparar os resultados da aplicação das técnicas de questionário e laddering nas mesmas populações, a pesquisa de Silva (2014) permitiu evidenciar que as relações entre percepções e valores pessoais eram mais claramente capturadas e explicitadas pela técnica laddering. A técnica de pesquisa laddering é constituída por entrevistas em profundidade (coleta), identificação de ladders (análise) e a representação dos dados em Mapeamento Hierárquico de Valor (MHV) (interpretação) na abordagem do modelo de Cadeia de Meios-fim (REYNOLDS; GUTMAN, 1988). Para Gutman (1991), os principais objetivos da laddering estão em analisar o conteúdo discursivo e descrever e organizar a estrutura cognitiva dos usuários sobre seu próprio comportamento em uma estrutura de associações de conceitos.

A partir do exposto, este artigo tem como objetivo propor uma análise que combina as percepções de valor das esferas de desenvolvimento (técnicos da Prefeitura Municipal de Porto Alegre) e ocupação (usuários) de empreendimentos habitacionais utilizando o mapeamento hierárquico de valor. A presente pesquisa busca avançar em relação às contribuições já feitas possibilitando a identificação e explicitação dos níveis mais abstratos presentes na percepção dos usuários e dos técnicos, permitindo a aproximação entre as diferentes perspectivas envolvidas no desenvolvimento e ocupação do produto habitação, o que pode indicar oportunidades de melhorias para o monitoramento de empreendimentos existentes e para o desenvolvimento de futuros EHIS.

\section{Metodologia \\ Estratégia de pesquisa}

Para este estudo adotou-se a estratégia de pesquisa construtiva (ou design science research). A pesquisa construtiva é definida como uma investigação capaz de produzir construções inovadoras, como modelos, planos, estruturas organizacionais, produtos comerciais, projetos de sistema de informação, ou uma combinação desses (LUKKA, 2003). Para Kasanen, Lukka e Siitonen (1993), essas construções inovadoras têm como intuito resolver problemas de relevância teórica e prática do mundo real e contribuir para a disciplina na qual é aplicada. A Figura 1(a) apresenta as características da pesquisa construtiva, enquanto a Figura 1(b) apresenta um comparativo dessas características com a presente pesquisa, mostrando que o estudo é adequado a esses princípios.

A avaliação da percepção de valor das esferas de desenvolvimento (técnicos) e ocupação (usuários) do produto habitação implica um problema do mundo real e de relevância prática no contexto da provisão habitacional, uma vez que busca obter informações que possibilitem entender de forma mais precisa o valor que está sendo entregue para o usuário dessa tipologia de produto em comparação com a expectativa de valor por parte dos técnicos das instituições públicas envolvidas em seu desenvolvimento. 
Figura 1 - Características da pesquisa construtiva e características da presente pesquisa

(a)

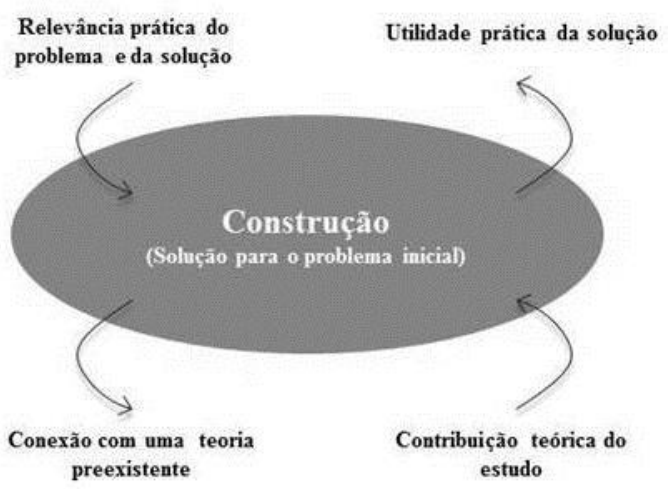

(b)

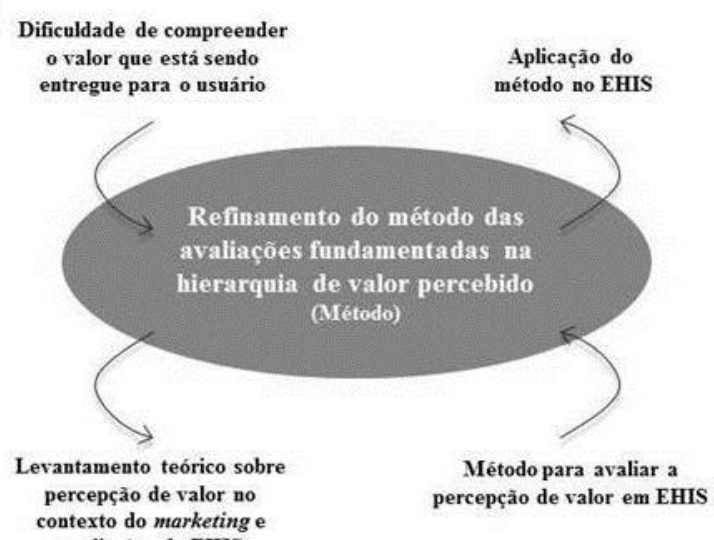

Fonte: Monteiro (2015) adaptado de Kasanen, Lukka e Siitonen (1993).

\section{Objeto de estudo}

Para o desenvolvimento desta pesquisa foi delimitado como objeto de estudo um dos EHIS previstos no escopo do Programa Integrado Entrada da Cidade (Piec), na cidade de Porto Alegre, RS. O Piec foi criado com o objetivo de melhorar a qualidade de vida da população que vive em condições precárias nas áreas de intervenção do programa por meio da reestruturação habitacional e urbana e da recuperação ambiental da região. Visando alcançar esse objetivo, o programa foi desenvolvido a partir de quatro grandes projetos:
(a) habitação;
(b) infraestrutura viária;
(c) valorização paisagística; e
(d) trabalho social.

Esse último foi desdobrado em duas linhas de ação: geração de trabalho e renda; e desenvolvimento comunitário.

A população beneficiária do Piec foi delimitada pelas famílias das comunidades, identificadas em 20 vilas irregulares localizadas na área de intervenção do programa. Essas áreas consideradas de risco caracterizam-se pela forte presença da subnormalidade habitacional (grande número de vilas irregulares em precárias condições de saneamento e salubridade), situação econômica degradada (vocação industrial e de serviços da região perdeu importância para o desenvolvimento da cidade para outras regiões) e localização geográfica estratégica (zona de ligação da cidade com a região metropolitana).

Com objetivo de atender á demanda dessas áreas, a Prefeitura Municipal de Porto Alegre (PMPA) estima que o Piec beneficie, após a conclusão dos
20 EHIS previstos, cerca de 3.775 famílias, que pertencem predominantemente à faixa de renda de zero a três salários mínimos. Desse total, estima-se que 1.408 famílias já tenham sido beneficiadas pelo Programa entre 2003 e 2013, com a implantação de oito EHIS. Entre essas famílias 853 são pertencentes às duas primeiras etapas de implantação do programa, as quais compreendem cinco empreendimentos avaliados nos estudos de Miron (2008) e Miron e Formoso (2009).

De acordo com o relatório da PMPA (PREFEITURA..., 2013), as demais 555 famílias beneficiadas são pertencentes à terceira etapa de implantação do Programa, realizada entre 2006 e 2013. Essa etapa corresponde a três empreendimentos: A.J. Renner, Bela Vista e Jardim Navegantes. Para o desenvolvimento desta pesquisa foram delimitados como população-alvo os beneficiários que residem no EHIS A.J. Renner, correspondendo a 58 famílias. A delimitação dessa população-alvo foi realizada a partir de reuniões com os técnicos da PMPA e se justifica pelo fato de esse empreendimento possuir maior tempo de ocupação em relação aos da terceira etapa de implantação do Programa.

\section{EHIS A.J. Renner}

O EHIS A.J. Renner foi entregue aos beneficiários em agosto de 2006. O empreendimento é composto de 57 unidades habitacionais com uma tipologia habitacional, sendo 57 sobrados com $42,25 \mathrm{~m}^{2}$ e 1 unidade habitacional para pessoa portadora de necessidades especiais com $49,50 \mathrm{~m}^{2}$. Além disso, o empreendimento contempla uma creche e uma praça. A Figura 2(a) apresenta o empreendimento A.J. Renner, enquanto a Figura 2(b) apresenta as tipologias mencionadas. De forma complementar, as Figuras 2(c) e 2(d) 
apresentam fotos do empreendimento obtidas do acervo pessoal dos pesquisadores.

\section{Questionário}

Para avaliação da percepção de valor dos usuários do EHIS A.J. Renner foi construído um questionário específico. $\mathrm{O}$ questionário foi estruturado com base em questionários utilizados em estudos anteriores que abordaram a percepção de valor dos usuários de EHIS (MIRON, 2008; MIRON; FORMOSO, 2009; BONATTO, 2010). De forma complementar, também foram realizadas reuniões com técnicos da PMPA envolvidos no desenvolvimento do EHIS (3 arquitetos, 2 engenheiros civis e 4 assistentes sociais do Departamento Municipal de Habitação - Demhab). Nessas reuniões com os técnicos foram geradas discussões sobre novos itens a serem considerados no questionário para a realização da avaliação.

Figura 2 - (a) Representação da implantação do EHIS A. J. Renner; (b) tipologias habitacionais; e (c) e (d) fotos

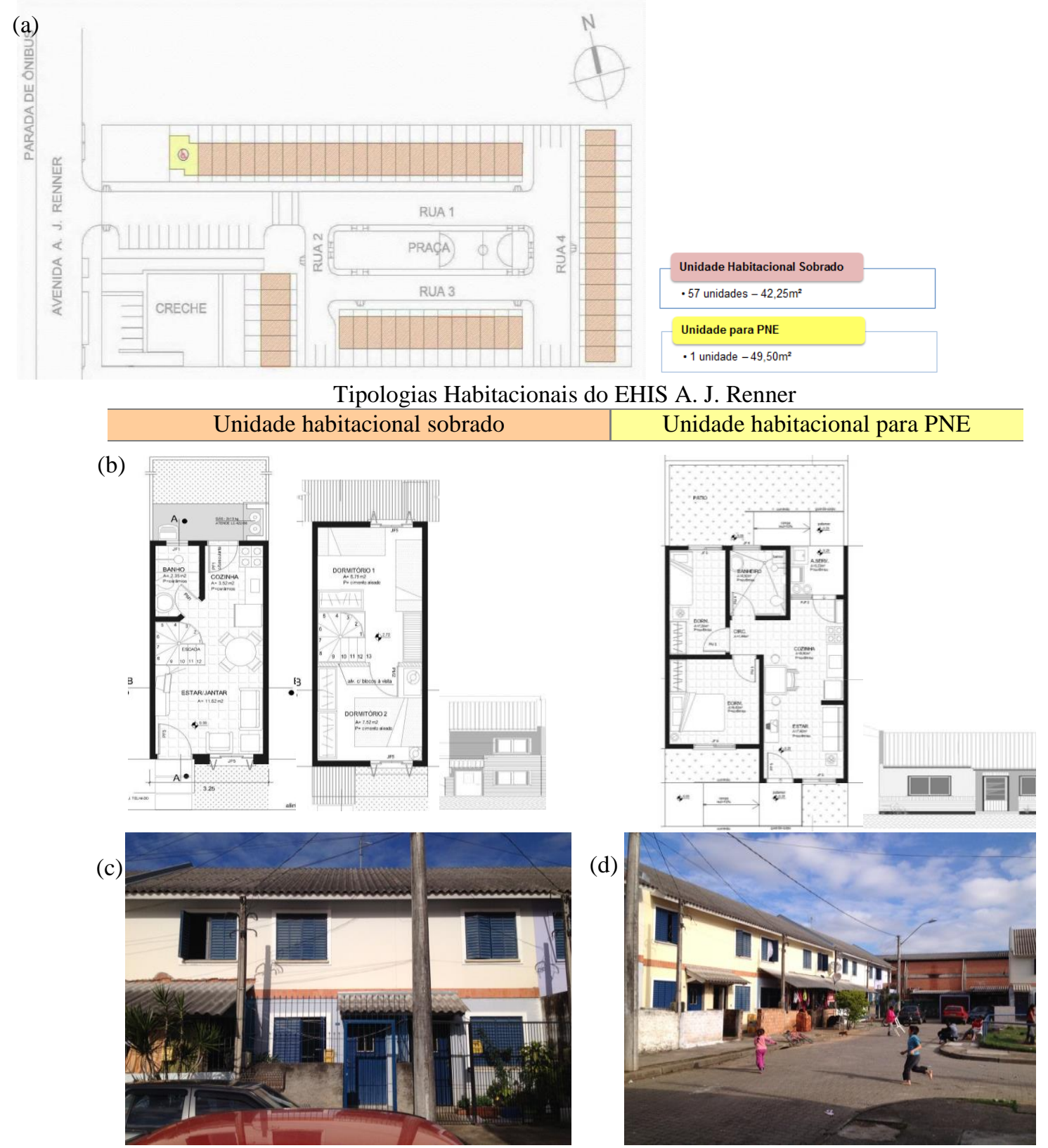

Fonte: (a) e (b) adaptado da PMPA (PREFEITURA..., 2013) e (c) e (d) acervo pessoal dos autores (2014). 
Figura 3 - Mapeamento de valor com base na percepção dos técnicos da PMPA (arquitetos, engenheiros, assistentes sociais e pesquisadores) envolvidos no processo de desenvolvimento do empreendimento

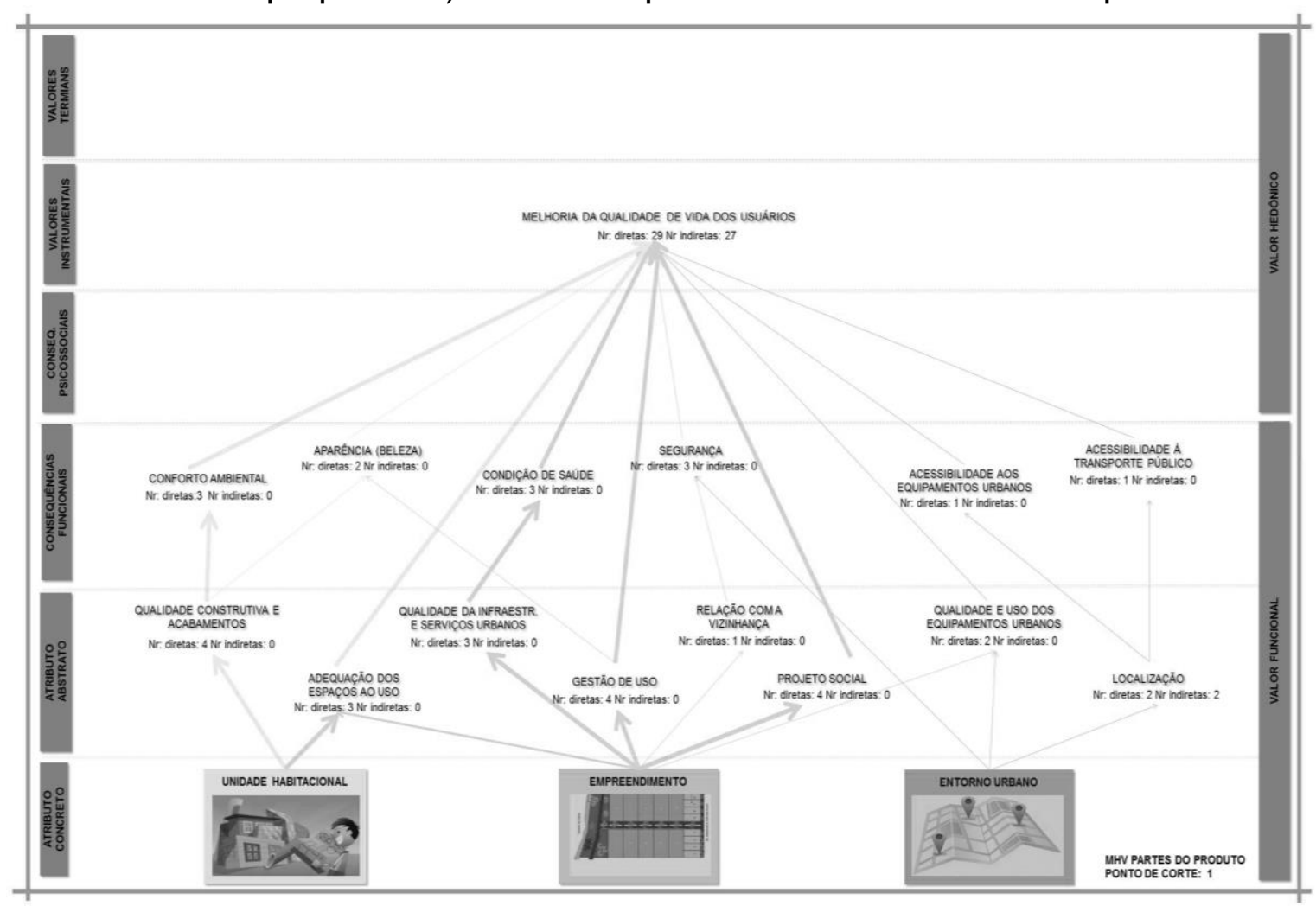

Fonte: Monteiro (2015.

A análise do questionário dos estudos anteriores e as reuniões com os técnicos auxiliaram na identificação dos atributos do produto (base do modelo), consequências de uso esperadas (nível intermediário do modelo) e objetivo do programa (topo do modelo). Tais informações possibilitaram a estruturação de uma hierarquia de valor com base na percepção dos técnicos da PMPA (valor desejado), conforme a Figura 3.

A partir da estrutura dessa hierarquia de valor desejado pelos técnicos (Figura 3) foi desenvolvido um questionário específico utilizado para a avaliação realizada nesta pesquisa. $\mathrm{O}$ questionário foi estruturado a partir de sete grandes seções:
(a) identificação do pesquisador;
(b) laddering;
(c) avaliação de satisfação com os projetos;
(d) serviços relacionados aos projetos;
(e) perfil dos usuários;
(f) permanência/evasão; e
(g) intenção de permanência das famílias beneficiárias no empreendimento.

A seção 1 teve como objetivo identificar dados para controle do pesquisador, como nome, data e número do questionário. A seção 2 teve como objetivo identificar as cinco melhores características do empreendimento onde o usuário reside e entender o porquê das escolhas e preferências a partir de uma entrevista em profundidade (laddering). Essa seção busca explicitar como os usuários percebem o produto EHIS e permite aos pesquisadores que seja realizada por meio de MHV uma análise comparativa entre o valor desejado (percepção dos técnicos da PMPA) e o valor recebido (percepção dos usuários dos EHIS). As seções 3 e 4 tiveram como objetivo avaliar o nível de satisfação dos usuários em relação ao produto EHIS (projetos e serviços). Para medir o percentual de satisfação dos usuários com o produto EHIS foram utilizadas perguntas fechadas e uma escala de cinco níveis, de muito insatisfeito a muito satisfeito, com um ponto neutro. Os itens questionados nessa seção foram organizados com base nos atributos do produto (unidade habitacional, empreendimento, entorno) e nas consequências de uso identificados no mapa de hierarquia de valor desejado pelos técnicos da PMPA (Figura 3), de forma a permitir que fossem verificados os níveis de satisfação dos 
usuários com o EHIS. A seção 5 teve como objetivo identificar o perfil dos moradores dos empreendimentos avaliados. A seção 6 teve como objetivo identificar se a família residente na unidade habitacional pertencia ao cadastro original de reassentamento do programa, enquanto a seção 7 teve como objetivo identificar a intenção de permanência dos usuários nos empreendimentos avaliados, assim como o principal motivo para permaner nele ou não. Essas duas últimas seções buscaram identificar os percentuais de permanência das famílias, indicador considerado relevante pelos técnicos da PMPA na análise dos resultados do programa.

\section{Plano amostral}

Para o cálculo do tamanho de amostra desta pesquisa utilizou-se a proporção (p) igual a 50\%, valor que representa a maior variância amostral possível e, consequentemente, o maior tamanho de amostra. O erro amostral (ع) utilizado foi de $10 \%$. Para o nível de confiança considerou-se $95 \%$. A Figura 4 mostra hachuradas em cinza mais escuro, as unidades habitacionais selecionadas com base no tamanho da amostra necessário de acordo com os valores adotados nesta pesquisa (36 unidades amostrais).

\section{Coleta de dados}

A coleta de dados no EHIS foi realizada nos dias 21 e 23 de outubro de 2014 (terça-feira e quarta- feira) por uma equipe de seis pessoas, organizadas em três duplas. A saída de campo ocorreu às $13 \mathrm{~h} 30 \mathrm{~min}$, e o retorno, às $17 \mathrm{~h} 30 \mathrm{~min}$. O tempo aproximado de coleta foi de $3 \mathrm{~h}$ ( $14 \mathrm{~h}$ às $17 \mathrm{~h}$ ), sendo 20 min para cada questionário. Para a coleta de dados com os usuários utilizou-se a técnica Soft Laddering. Para Grunert, Grunert e Sorensen (1995), a Soft Laddering apresenta características de uma entrevista em profundidade, pois permite o discurso livre por parte do entrevistado, e desta maneira o entrevistador conduz a entrevista quase sem restrições, permitindo que se obtenha o maior número de dados possível para que seja feita a construção das escalas.

\section{Análise dos dados}

Para análise dos dados obtidos foram utilizados os softwares Statistical Package for the Social Sciences $\left(\right.$ SPSS $\left.^{\circledR}\right)$, Excel $^{\circledR}$ e LadderUX. Para a elaboração do banco de dados optou-se por dividir em dois arquivos de Excel $^{\circledR}$, sendo um para as questões abertas e outro para as questões fechadas do questionário. Essa divisão foi previamente definida visando à posterior importação do banco de dados para programas estatísticos diferentes, sendo os dados das questões abertas para o LadderUX, e o das questões fechadas para o SPSS $^{\circledR}$.

Figura 4 - Representação da implantação do EHIS A.J. Renner com a demarcação das unidades habitacionais com base no tamanho da amostra necessário

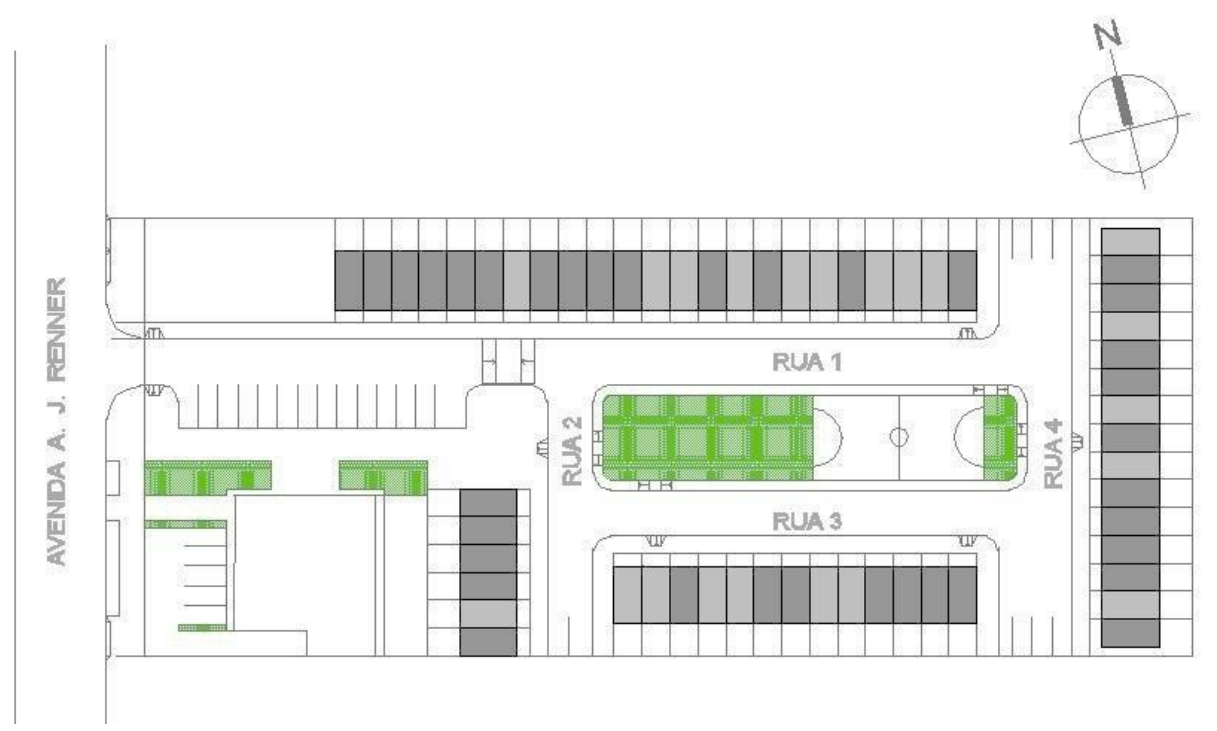

Fonte: Monteiro (2015) e adaptado da PMPA (2013). 
Especificamente para a análise dos dados obtidos por meio das questões fechadas do questionário foram utilizadas técnicas estatísticas descritivas. Para validação do questionário para avaliação foi utilizado o cálculo do Alpha de Cronbach (HAIR JUNIOR et al., 2009). Para análise dos dados obtidos por meio das questões abertas (técnica laddering) foram seguidas as etapas recomendadas por Reynolds e Gutman (1988):

(a) análise de conteúdo;

(b) construção da matriz de implicação;

(c) construção do mapa hierárquico de valor; e

(d) determinação das orientações de percepções dominantes por meio de um ponto de corte respectivamente.

Para Reynolds e Gutman (1988), a etapa (a) consiste na análise e padronização dos termos identificados por meio da técnica laddering (REYNOLDS; GUTMAN, 1988). Segundo Veludo-de-Oliveira e Ikeda (2008), é na fase de análise que são realizadas as classificações das orações resultantes da técnica laddering em: (A) atributos de um produto; (C) consequências de uso de um produto; e (V) valores pessoais dos indivíduos, ou cadeias A-C-V. Nesse sentido, visando obter resultados mais confiáveis, foram realizadas reuniões entre os pesquisadores envolvidos nas análises de dados nas quais foram apresentadas e discutidas as cadeias resultantes da técnica, ocasionando sucessivos refinamentos. A partir dessa classificação, as ladders foram sequencialmente adicionadas na ferramenta LadderUX.

$\mathrm{Na}$ etapa (b) foi construída a matriz de implicação a partir da inserção das ladders de cada responde na fase anterior. Segundo Reynolds e Gutman (1988), a matriz representa a quantidade de conexões entre os elementos, ou seja, quantas vezes cada elemento leva ao alcance de um atributo, consequência ou valor. Essas conexões são representadas a partir de relações diretas e indiretas entre os elementos, as quais formam coordenadas para a construção do MHV (REYNOLDS; GUTMAN, 1988).

$\mathrm{Na}$ etapa (c) foi elaborado o MHV. Segundo os mesmos autores, o MHV corresponde a um diagrama na forma de árvore que presenta graficamente as conexões ou associações entre os atributos, consequências e valores levantados a partir das questões abertas do questionário. Essas associações são representadas por meio de linhas, e quanto mais espessas forem, maior a relação entre os elementos, ou seja, mais percebidos os elementos pelos usuários.

Tendo em vista que em um primeiro momento o MHV pode se apresentar de forma confusa, devido ao grande número de relações entre os elementos, na etapa (d) foi estipulado um ponto de corte. Reynolds e Gutman (1988) recomendam que esse ponto represente o número mínimo de vezes que determinada relação deva ocorrer para que seja considerada relevante no mapeamento. Para Reynolds e Gutman (1988), o ponto de corte ideal é aquele que consegue representar cerca de dois terços de todas as relações da matriz de implicação. Nesta pesquisa o ponto de corte utilizado foi 7 , o qual representou $79 \%$ do total de relações do MHV.

Por fim, foi gerado um MHV com sobreposição das percepções de valor de técnicos e usuários, com a inserção dos resultados de satisfação dos usuários (sobre atributos e consequências do produto EHIS). Os principais resultados desta pesquisa são discutidos na sequência.

\section{Resultados da avaliação}

\section{Análise dos resultados}

\section{Perfil do usuário}

A Figura 5 apresenta o perfil do responsável pela residência por meio do sexo, grau de escolaridade e idade. No que tange ao sexo, $70 \%$ dos responsáveis correspondem ao feminino, enquanto $30 \%$ correspondem ao sexo masculino. Quanto à escolaridade, destaca-se o número de responsáveis com $1^{\circ}$ grau incompleto, correspondendo a $43 \%$, e em relação à idade, $51 \%$ são adultos jovens. A Figura 5 apresenta uma comparação entre a situação anterior (2006) e uma posterior (2014) ao reassentamento para a atual área de moradia para a condição de ocupação/trabalho e da renda média atual. No tocante à ocupação antes do reassentamento, $68 \%$ estavam trabalhando, sendo $60 \%$ com emprego formal e $8 \%$ assalariados com emprego informal. Na situação posterior ao reassentamento, $62 \%$ estavam trabalhando, sendo apenas $30 \%$ com emprego formal. Um ponto importante para redução de responsáveis trabalhando é o aumento do número de aposentados, de $5 \%$ para $27 \%$. Quanto à renda média familiar, predominam as faixas que recebem entre $\mathrm{R} \$ 501,00$ e $\mathrm{R} \$ 1.000,00$ (38\%), e entre $\mathrm{R} \$$ $1.001,00$ e $\mathrm{R} \$ 1.500,00$ (24\%). 
Figura 5 - Perfil dos usuários

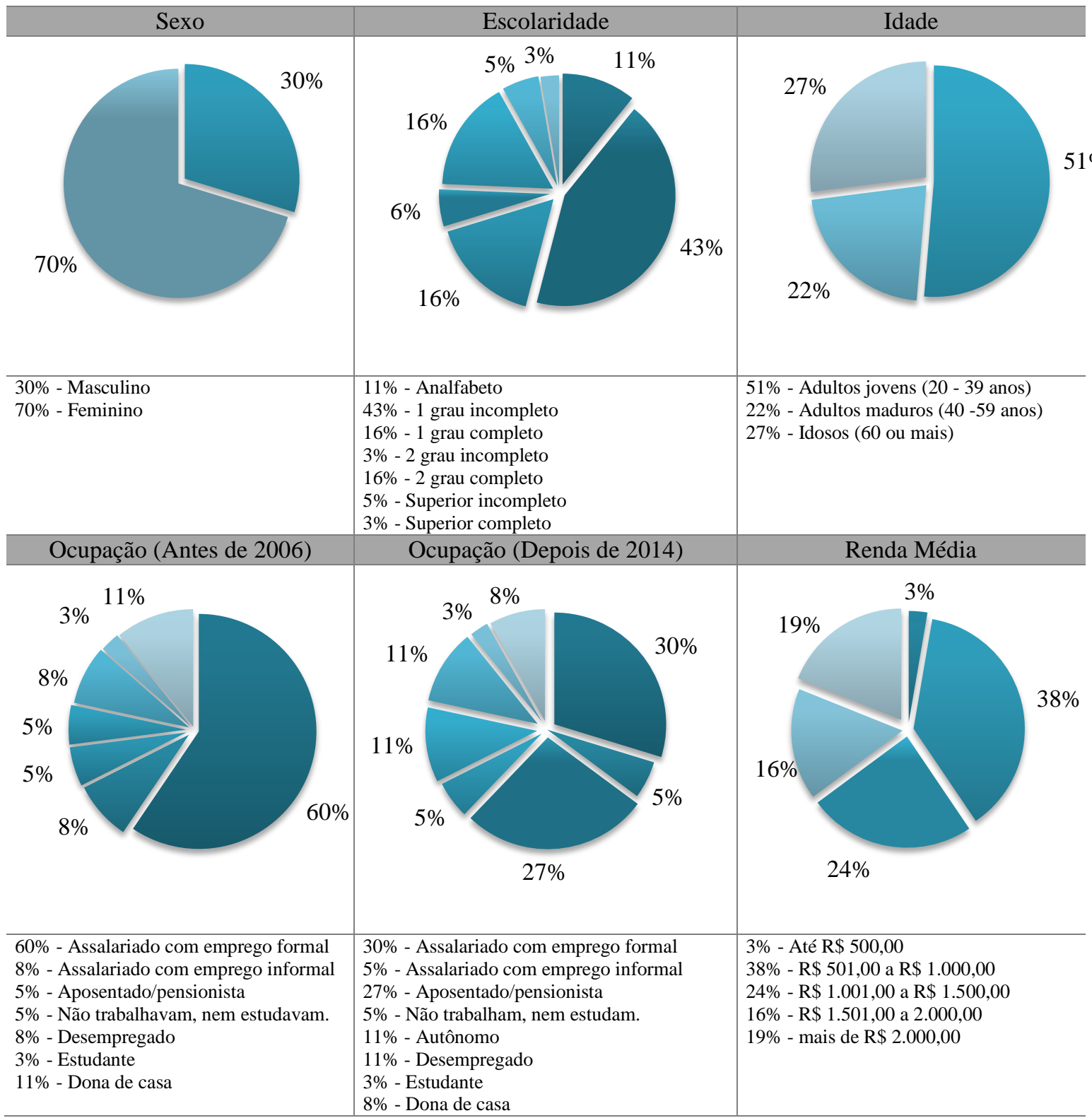

Fonte: Monteiro (2015).

\section{Permanência e intenção de permanência dos usuários no empreendimento}

No tocante à permanência dos usuários no empreendimento, foi possível observar índices positivos. A Figura 6(a) demonstra que $89 \%$ dos moradores pertencem ao cadastro original do programa. Dos $11 \%$ não pertencentes $3 \%$ adquiriram a UH por meio da compra, enquanto $8 \%$ por meio de troca de UH (localizada em outra vila ou bairro). Por outro lado, a Figura 6(b) demonstra que 59\% dos moradores têm intenção de permanecer, enquanto $41 \%$ possivelmente iriam embora, indicando a necessidade de monitoramento da ocupação e das possíveis causas futuras de evasão dos moradores do empreendimento.

A Figura 7(a) busca apresentar a relação entre a intenção de permanência dos usuários no empreendimento e as partes que compõem esse produto, os atributos. Considerando que 59\% dos usuários têm intenção de permanecer, os motivos para permanência estão relacionados aos seguintes atributos do produto: ao empreendimento (27\%), ao entorno urbano (27\%), à unidade habitacional $(5 \%)$ e ao projeto social (3\%). A Figura 7(b) apresenta os motivos para a não permanência dos usuários no empreendimento, dos quais se destacam: a unidade habitacional (24\%), o 
empreendimento (11\%), o entorno urbano (3\%) e o projeto social $(3 \%)$. De modo geral, é possível observar que o principal motivo para permanência tende a estar relacionado ao entorno urbano, enquanto a não permanência tende a estar relacionada à unidade habitacional.

A Figura 8(a) apresenta, de forma complementar, as consequências relativas ao uso do produto relacionado à intenção de permanência no empreendimento (59\%). Entre as consequências de uso relacionadas aos motivos para permanência destacam-se a segurança do empreendimento $(31,8 \%)$ e a familiaridade com o lugar $(27,3 \%)$. Já a Figura 8(b) apresenta os motivos para a não permanência no empreendimento (41\%), dos quais se destacam os problemas de adaptação à unidade habitacional $(60 \%)$ e os problemas de relacionamento com os vizinhos $(26,7 \%)$. No que se refere à adequação dos espaços aos usos, os motivos estão vinculados à necessidade de mais espaço na unidade habitacional, principalmente em relação ao pátio. Quanto ao relacionamento com os vizinhos, os motivos estão vinculados a problemas que já existiam na antiga área de moradia, como maus hábitos de higiene ou rivalidade entre famílias.

Figura 6 - Permanência e intenção de permanência

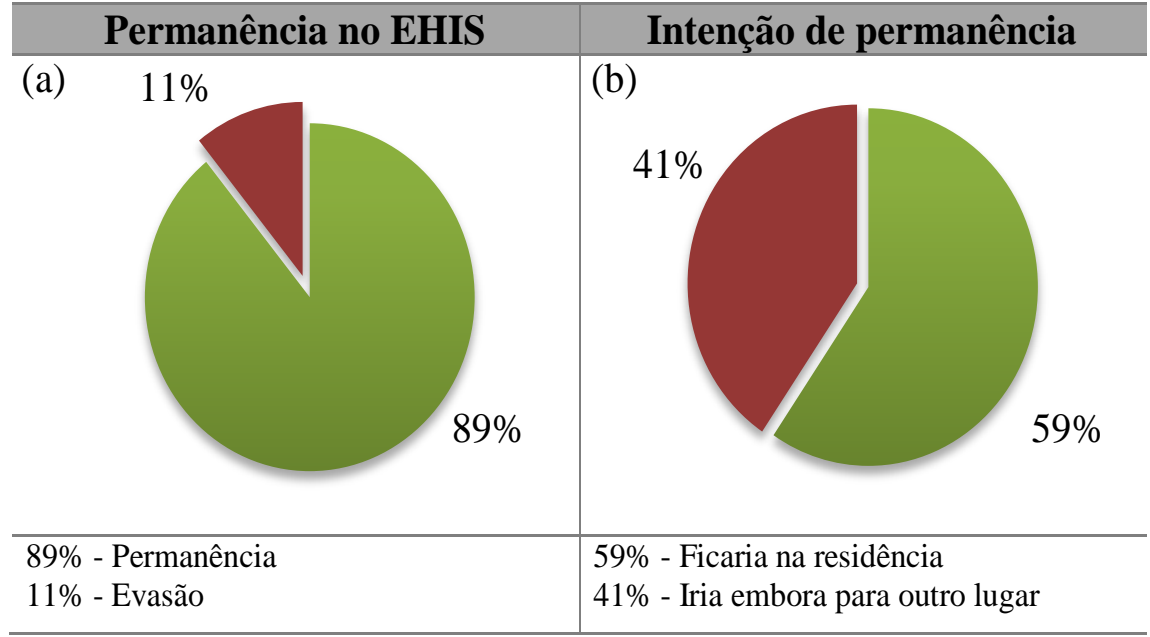

Fonte: Monteiro (2015).

Figura 7 - Motivos para permanecer ou não permanecer no EHIS (produto)

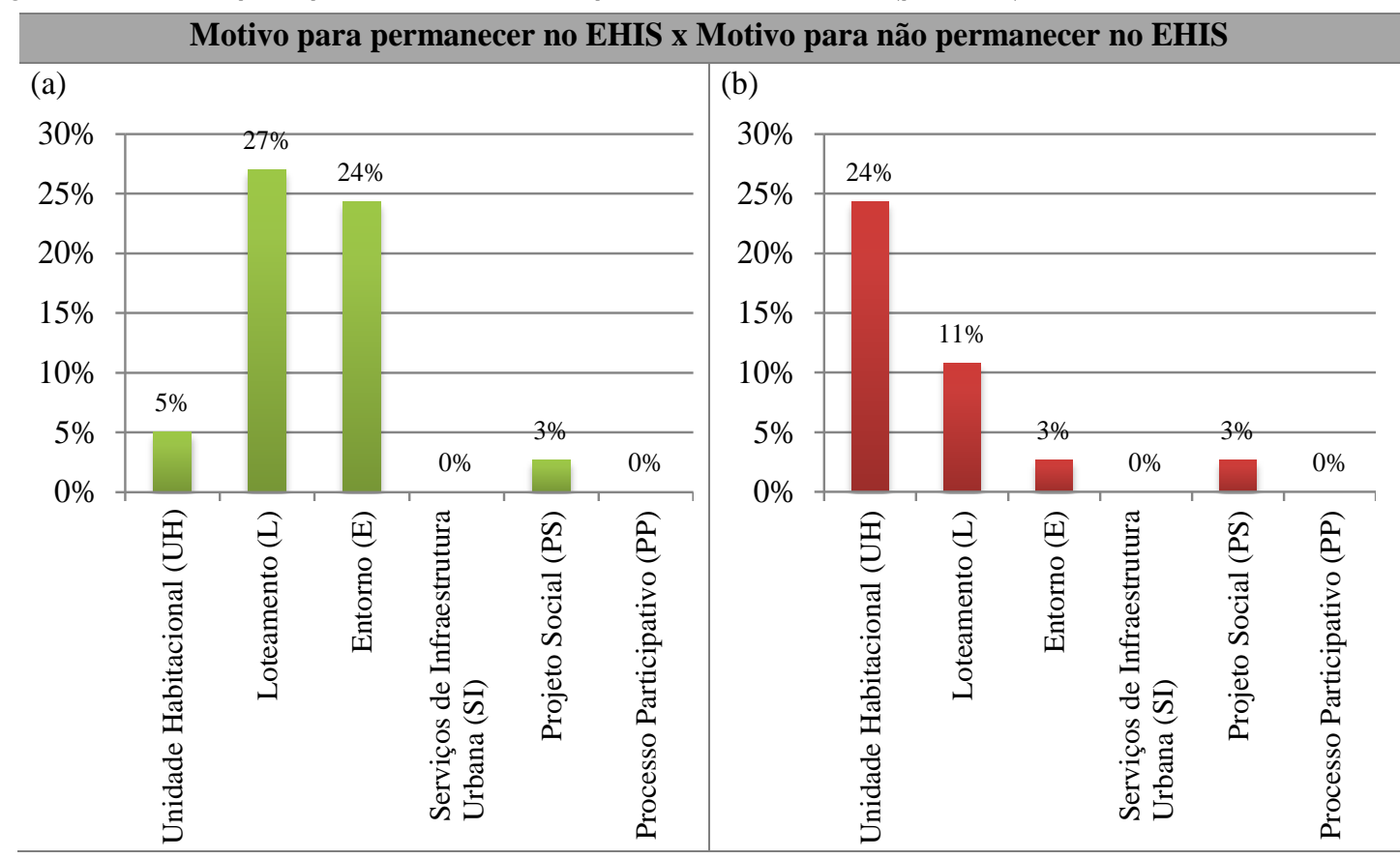

Fonte: Monteiro (2015).

46 Monteiro, D. A. B.; Miron, L. I. G.; Shigaki, J. S.; Echeveste, M. E. S. 


\section{Satisfação com o produto EHIS (projetos e serviços)}

A partir dos resultados demonstrados na Tabela 1 é possível perceber índices de satisfação positivos em relação aos projetos e serviços que compõem o produto EHIS. Entre os destaques estão os altos índices de satisfação com os serviços relacionados à infraestrutura urbana. Essa situação demonstra um panorama similar ao apontado por Miron (2008), no qual a infraestrutura urbana foi o principal benefício percebido pelos moradores de três EHIS do Piec. Destaca-se também a satisfação com o entorno urbano, relacionada principalmente à familiaridade dos moradores com o local, e conforme apontando no resultado de retenção, $89 \%$ são originários do cadastro do programa. Os aspectos negativos, por sua vez, condizem, em sua maioria, com a unidade habitacional. Entre esses aspectos destacam-se o conforto ambiental $(59,9 \%)$, a qualidade construtiva $(48,6 \%)$ e o espaço físico do pátio da unidade habitacional $(54,1 \%)$

\section{Mapeamento hierárquico de valor percebido pelos usuários}

Por meio da técnica laddering e da ferramenta LadderUX foi possível estruturar o mapeamento de valor percebido pelos usuários do empreendimento avaliado. $\mathrm{O}$ mapeamento atua de forma complementar às técnicas empregadas anteriormente com base na área ambiente comportamento, ao identificar não apenas o que mas também o motivo por que determinados elementos são mais importantes para formação de valor do que outros (VELUDO-DE-OLIVEIRA; IKEDA, 2008).

A cadeia empreendimento - qualidade da infraestrutura e serviços urbanos - fato de não ter mais alagamentos - condição de saúde igualdade de direitos resulta na combinação mais forte no MHV. Essa cadeia cognitiva reforça os resultados apontados no estudo de Miron (2008), no qual os usuários perceberam a infraestrutura como o principal benefício. Uma possível explicação para tal fato seriam as condições precárias de moradia anterior ao reassentamento, carentes de infraestrutura e serviços básicos de saneamento, como coleta de lixo, fornecimento de água e energia elétrica.

A cadeia empreendimento - relação com a vizinhança - segurança - tranquilidade liberdade resulta na segunda combinação mais forte no MHV. Essa cadeia reforça o entendimento de que a relação de proximidade entre os vizinhos resulta no aumento da sensação de segurança no empreendimento. Esse fato pode ser explicado em virtude do sistema de vigilância cidadã entre os próprios vizinhos, como descrito por Jacobs (2000). A sensação de segurança representa um importante benefício percebido pelos usuários, uma vez que afeta diretamente o "direito de ir $e$ vir" dos usuários dentro do empreendimento.

Figura 8 - Motivos para permanecer e não permanecer no EHIS (consequências relativas ao uso)

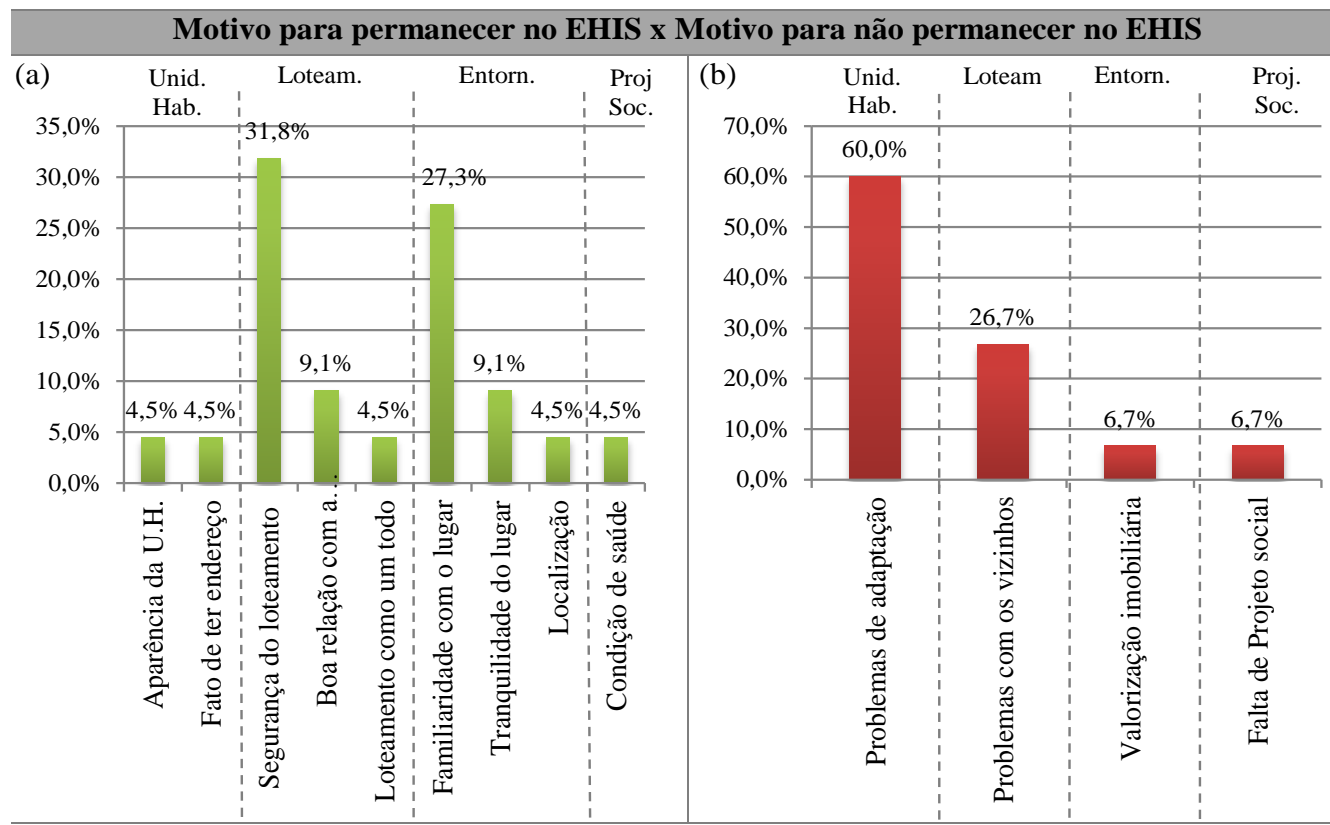

Fonte: Monteiro (2015). 
Tabela 1 - Resultados da avaliação de satisfação dos usuários do o EHIS A.J. Renner Tabela ger al da avalição de satisfação dos usuários do EHIS A. J. Renner

\begin{tabular}{|c|c|c|c|c|c|c|c|c|c|c|}
\hline & & \multirow[b]{2}{*}{$\begin{array}{c}\text { Casos } \\
\text { (n) }\end{array}$} & \multirow{2}{*}{\multicolumn{4}{|c|}{ Naito ESCALA DO QUESTIONÁRIO }} & \multirow[b]{2}{*}{$\begin{array}{c}\text { Muito } \\
\text { Satisfeito }\end{array}$} & \multicolumn{3}{|c|}{ ESCALA SOMADA } \\
\hline & & & & & & Satiffeito & & $\mathrm{MI}+\mathrm{I}$ & Neutro & $\mathrm{MS}+\mathrm{S}$ \\
\hline \multirow{24}{*}{ 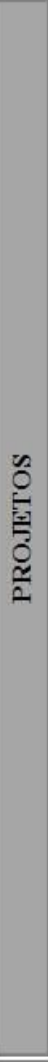 } & \multicolumn{10}{|c|}{ UNIDADE HABITACIONAL (UH) } \\
\hline & \multicolumn{10}{|c|}{ QUALIDADE DA UNIDADE HABITACIONAL } \\
\hline & Espaço físico da casa & 36 & $5,4 \%$ & $21,6 \%$ & $13,5 \%$ & $40,5 \%$ & $18,9 \%$ & $27,0 \%$ & $13,5 \%$ & $59,5 \%$ \\
\hline & Espaço físico do pátio da casa & 36 & $10,8 \%$ & $43,2 \%$ & $13,5 \%$ & $27,0 \%$ & $5,4 \%$ & $54,1 \%$ & $13,5 \%$ & $32,4 \%$ \\
\hline & Qualidade construtiva da casa & 36 & $8,1 \%$ & $40,5 \%$ & $16,2 \%$ & $29,7 \%$ & $5,4 \%$ & $48,6 \%$ & $16,2 \%$ & $35,1 \%$ \\
\hline & Conforto ambiental da casa & 36 & $10,8 \%$ & $48,6 \%$ & $16,2 \%$ & $24,3 \%$ & $0,0 \%$ & $59.5 \%$ & $16,2 \%$ & $24,3 \%$ \\
\hline & Aparência casa quando entregue & 36 & - & $16,2 \%$ & $10,8 \%$ & $59,5 \%$ & $13,5 \%$ & $16,2 \%$ & $10,8 \%$ & $73,0 \%$ \\
\hline & Fato de ter endereço & 36 & $2,7 \%$ & $2,7 \%$ & $10,8 \%$ & $59,5 \%$ & $24,3 \%$ & $5,4 \%$ & $10,8 \%$ & $83,8 \%$ \\
\hline & \multicolumn{10}{|l|}{ LOTEAMENTO (L) } \\
\hline & \multicolumn{10}{|l|}{ QUALIDADE DO LOTEAMENTO } \\
\hline & Uso das praças do loteamento & 36 & $16,2 \%$ & $18,9 \%$ & $10,8 \%$ & $43,2 \%$ & $10,8 \%$ & $35,1 \%$ & $10,8 \%$ & $54,1 \%$ \\
\hline & Espaço fisico do loteamento & 36 & $27,3 \%$ & $27,3 \%$ & $27,3 \%$ & $15,2 \%$ & $3,0 \%$ & $54,5 \%$ & $27,3 \%$ & $18,2 \%$ \\
\hline & Relação com a vizinhança & 36 & $2,7 \%$ & $10,8 \%$ & $10,8 \%$ & $59,5 \%$ & $16,2 \%$ & $13,5 \%$ & $10,8 \%$ & $75,7 \%$ \\
\hline & Sensação de segurança de dia & 36 & $2,7 \%$ & $8,1 \%$ & $5,4 \%$ & $62,2 \%$ & $21,6 \%$ & $10,8 \%$ & $5,4 \%$ & $83,8 \%$ \\
\hline & Sensação de segurança à noite & 36 & - & $10,8 \%$ & $2,7 \%$ & $62,2 \%$ & $24,3 \%$ & $10,8 \%$ & $2,7 \%$ & $86,5 \%$ \\
\hline & Aparência do lot. quando entreg. & 36 & $2,7 \%$ & $13,5 \%$ & $18,9 \%$ & $54,1 \%$ & $10,8 \%$ & $16,2 \%$ & $18,9 \%$ & $64,9 \%$ \\
\hline & \multicolumn{10}{|l|}{ ENTORNO (E) } \\
\hline & \multicolumn{10}{|l|}{ QUALIDADE DO ENTORNO } \\
\hline & Uso dos parques & 36 & - & $5,6 \%$ & $13,9 \%$ & $52,8 \%$ & $27,8 \%$ & $5,6 \%$ & $13,9 \%$ & $80,6 \%$ \\
\hline & Localização do loteamento & 36 & $2,7 \%$ & - & $13,5 \%$ & $54,1 \%$ & $29,7 \%$ & $2,7 \%$ & $13,5 \%$ & $83,8 \%$ \\
\hline & Acessibilidade aos equip. urb. & 36 & - & $2,7 \%$ & $10,8 \%$ & $51,4 \%$ & $35,1 \%$ & $2,7 \%$ & $10,8 \%$ & $86,5 \%$ \\
\hline & Acessibilidade a transp. coletivo & 36 & - & $5,4 \%$ & $16,2 \%$ & $51,4 \%$ & $27,0 \%$ & $5,4 \%$ & $16,2 \%$ & $78,4 \%$ \\
\hline & Sensação de segurança de dia & 36 & - & $27,0 \%$ & $13,5 \%$ & $51,4 \%$ & $8,1 \%$ & $27,0 \%$ & $13,5 \%$ & $59,5 \%$ \\
\hline & Sensação de segurança à noite & 36 & $10,8 \%$ & $27,0 \%$ & $13,5 \%$ & $40,5 \%$ & $8,1 \%$ & $37,8 \%$ & $13,5 \%$ & $48,6 \%$ \\
\hline \multirow{21}{*}{ 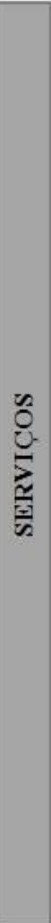 } & \multicolumn{10}{|c|}{ SERVIÇOS RELACIONADOS A INFRAESTRUTURA URBANA (SI) } \\
\hline & \multicolumn{10}{|c|}{ QUALIDADE DOS SERVIÇOS RELACIONADOS À INFRAESTRUTURA URBANA } \\
\hline & Recolhimento de lixo & 36 & - & $8,1 \%$ & $5,4 \%$ & $45,9 \%$ & $40,5 \%$ & $8,1 \%$ & $5,4 \%$ & $86,5 \%$ \\
\hline & Fornecimento de água & 36 & - & $2,7 \%$ & - & $67,6 \%$ & $29,7 \%$ & $2,7 \%$ & - & $97,3 \%$ \\
\hline & Fornecimento de luz & 36 & - & - & $2,7 \%$ & $64,9 \%$ & $32,4 \%$ & - & $2,7 \%$ & $97,3 \%$ \\
\hline & Fato de ter esgoto & 36 & $5,4 \%$ & $5,4 \%$ & $2,7 \%$ & $59,5 \%$ & $27,0 \%$ & $10,8 \%$ & $2,7 \%$ & $86,5 \%$ \\
\hline & Pav imentação de ruas e calçadas & 36 & - & $5,4 \%$ & $5,4 \%$ & $67,6 \%$ & $21,6 \%$ & $5,4 \%$ & $5,4 \%$ & $89,2 \%$ \\
\hline & Pagamento de taxas & 36 & - & $10,8 \%$ & $18,9 \%$ & $59,5 \%$ & $10,8 \%$ & $10,8 \%$ & $18,9 \%$ & $70,3 \%$ \\
\hline & \multicolumn{10}{|l|}{ PROJET O SOCIAL (PS) } \\
\hline & \multicolumn{10}{|c|}{ QUALIDADE DO PROJETO SOCIAL } \\
\hline & Oferta de cursos profis. & 11 & - & $27,3 \%$ & $18,2 \%$ & $27,3 \%$ & $27,3 \%$ & $27,3 \%$ & $18,2 \%$ & $54,5 \%$ \\
\hline & Acesso a emprego & 34 & - & - & $32,4 \%$ & $55,9 \%$ & $11,8 \%$ & - & $32,4 \%$ & $67,6 \%$ \\
\hline & Acesso a crédito & 36 & - & $11,1 \%$ & $16,7 \%$ & $58,3 \%$ & $13,9 \%$ & $11,1 \%$ & $16,7 \%$ & $72,2 \%$ \\
\hline & Reunião com técnicas sociais & 11 & $9,1 \%$ & $27,3 \%$ & $36,4 \%$ & $27,3 \%$ & - & $36,4 \%$ & $36,4 \%$ & $27,3 \%$ \\
\hline & Oficinas de como usar a casa & 5 & $20,0 \%$ & $20,0 \%$ & - & $60,0 \%$ & - & $40,0 \%$ & - & $60,0 \%$ \\
\hline & Condição de saúde & 36 & $2,7 \%$ & $21,6 \%$ & $8,1 \%$ & $54,1 \%$ & $13,5 \%$ & $24,3 \%$ & $8,1 \%$ & $67,6 \%$ \\
\hline & \multicolumn{10}{|c|}{ PROCESSO PARTICIPATIVO (PP) } \\
\hline & \multicolumn{10}{|l|}{ GESTÃO DE USO } \\
\hline & Organização assoc. de morad. & 10 & - & $30,0 \%$ & $10,0 \%$ & $40,0 \%$ & $20,0 \%$ & $30,0 \%$ & $10,0 \%$ & $60,0 \%$ \\
\hline & Manutenção lot. pela pref. & 35 & $5,7 \%$ & $22,9 \%$ & $11,4 \%$ & $40,0 \%$ & $20,0 \%$ & $28,6 \%$ & $11,4 \%$ & $60,0 \%$ \\
\hline & Manutenção lot. pelos morad. & 36 & $10,8 \%$ & $21,6 \%$ & $21,6 \%$ & $32,4 \%$ & $13,5 \%$ & $32,4 \%$ & $21,6 \%$ & $45,9 \%$ \\
\hline
\end{tabular}

Fonte: Monteiro (2015).

48 Monteiro, D. A. B.; Miron, L. I. G.; Shigaki, J. S.; Echeveste, M. E. S. 
A cadeia entorno urbano - qualidade e uso dos equipamentos urbanos - sociabilidade familiaridade - felicidade resulta na terceira combinação mais forte no MHV. Segundo a percepção dos usuários, as melhorias dos equipamentos urbanos são decorrentes da valorização da área, principalmente em virtude da implantação da Arena do Grêmio (estádio de um time de futebol de Porto Alegre). Algumas praças da área e o parque (Mascarenhas de Moraes) ganharam novos equipamentos, impulsionando a sociabilidade e a familiaridade entre os moradores da área com os visitantes de outras áreas da cidade.

A cadeia unidade habitacional - sentimento de posse - pertencimento ao local resulta na combinação mais fraca no MHV. Com base na percepção dos usuários é possível inferir que os elementos relacionados à unidade habitacional representam os benefícios menos percebidos pelos usuários no empreendimento. Pode-se observar por meio desta cadeia cognitiva que o sentimento de posse relacionado à unidade habitacional gera o valor instrumental de sentimento de pertencimento, o qual influência em aspectos de permanência desses usuários no empreendimento investigado, conforme evidenciado nesta pesquisa.

\section{Comparação entre o valor desejado (técnicos) e o percebido (usuários)}

Os resultados da avaliação do empreendimento referentes à técnica laddering e às questões de satisfação são mostrados de forma combinada na Figura 10, na qual as percepções de técnicos e usuários são sobrepostas em um único MHV. Comparando a hierarquia de valor desejado, definida com base na percepção dos técnicos da PMPA, com a hierarquia de valor percebido, com base na percepção dos usuários, ficam evidentes as novas relações identificadas a partir dos resultados da avaliação. Tais relações foram possibilitadas a partir da inserção da técnica laddering ao questionário e permitem as inferências apresentadas a seguir.

Figura 9 - Mapeamento de valor com base na percepção dos usuários

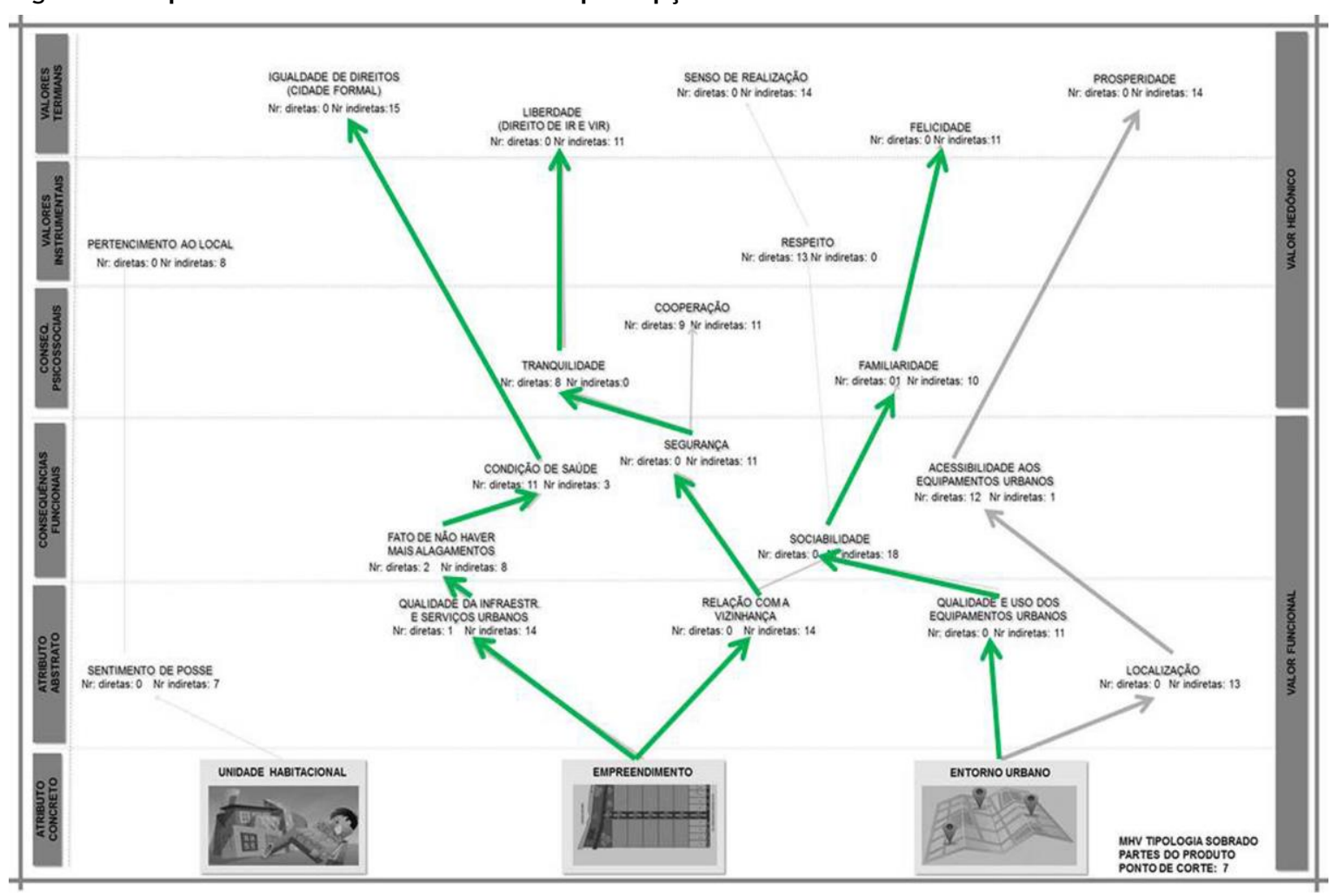

Fonte: Monteiro (2015). 
A unidade habitacional é, entre os atributos avaliados, a que menos apresenta benefícios desejados e percebidos, representando, portanto, a maior divergência entre as percepções dos técnicos e as dos usuários. De modo geral, os usuários percebem a qualidade construtiva e o conforto ambiental do imóvel como benefícios, conforme representado na Figura 10. Observa-se que os dados qualitativos da técnica laddering reforçam os dados quantitativos da seção de satisfação do questionário, uma vez que esses mesmos itens apresentaram elevados índices de insatisfação, $48,6 \%$ e $59,5 \%$ respectivamente. A adequação dos espaços aos usos também não é um benefício percebido pelos usuários, uma vez que o projeto desconsidera as particularidades dos diversos arranjos familiares da população cadastrada no programa para o dimensionamento do imóvel. Esse tipo de problema já havia sido identificado em pesquisas anteriores (MIRON, 2008; LEITE, 2005) e, como evidenciado nesta pesquisa, tende a estar relacionado à não permanência dos usuários no empreendimento $(60 \%)$.

Já o sentimento de posse, que não havia sido identificado na hierarquia de valor desejado pelos técnicos, aparece como um importante benefício percebido pelos usuários da unidade habitacional, uma vez que gera o sentimento de pertencimento ao local e tende a evitar a saída deles do empreendimento. A aparência, por sua vez, é um benefício desejado e percebido na unidade habitacional e pode ser explicado pela comparação que o usuário tende a fazer com a condição de moradia anterior, como explicam Moraes et al. (2002).

O empreendimento é, entre os atributos avaliados, o que mais apresenta benefícios desejados e percebidos, representando, portanto, uma convergência entre as percepções dos técnicos e dos usuários. Entre as relações mais evidentes no mapa está a qualidade da infraestrutura e dos serviços urbanos, diretamente vinculada à condição de saúde e ao valor terminal de sensação de igualdade de direitos (acesso à cidade formal), a qual não havia sido identificada na preparação da avaliação pelos técnicos, mas, no entanto, emergiu das respostas dos usuários. Assim, a igualdade de direitos tende a explicar o porquê de a infraestrutura ser tão importante para essa população, como já apontado nos estudos de Miron (2008), Miron e Formoso (2009) e Bonatto (2010).

Quanto ao entorno urbano, os usuários tendem a perceber como principal benefício a localização do empreendimento e a qualidade e uso dos equipamentos urbanos do entorno, conforme representado na Figura 10. A fácil localização aos diversos setores da cidade mantém uma forte relação com a acessibilidade aos equipamentos urbanos (hospitais, praças e escolas). A qualidade dos equipamentos urbanos também é um benefício desejado pelos técnicos e percebido pelos usuários, uma vez que grande parte dos moradores reconheceu haver melhorias nesses espaços, principalmente após a implementação da Arena do Grêmio.

A partir dos resultados desta avaliação e entre os itens avaliados, a unidade habitacional representa potenciais oportunidades de melhorias ao apresentar os maiores índices de insatisfação, os benefícios menos percebidos e consequentemente o maior motivo para a saída dos usuários do empreendimento (24\%). Aparentemente os problemas das unidades habitacionais estão relacionados ao escopo de projeto (especialmente pela não consideração da diversidade de arranjos domiciliares da população), aos problemas de execução da obra e consequentemente aos problemas gerenciais da PMPA. Contudo, se as melhorias nas unidades habitacionais fossem priorizadas, assim como a manutenção dos benefícios identificados como mais importantes, seria possível que efetivamente ocorresse a melhoria na qualidade de vida dessa população com a consequente permanência desses usuários no EHIS investigado.

\section{Considerações finais}

O presente artigo visou a uma análise que combinasse as percepções de valor das esferas de desenvolvimento (técnicos da Prefeitura Municipal de Porto Alegre: arquitetos, engenheiros e assistentes sociais) e ocupação (usuários) de empreendimentos habitacionais utilizando um modelo hierárquico de valor percebido. Entre as principais contribuições da pesquisa está a possibilidade de comparação e aproximação entre as esferas de desenvolvimento e ocupação envolvidas nos EHIS. A sobreposição dos principais resultados da avaliação, incluindo as análises estatísticas descritivas e a laddering, permitiu um formato de apresentação de resultados que resume um grande conjunto de dados, facilitando a compreensão sobre as percepções de valor e evidenciando algumas oportunidades de melhoria para empreendimentos futuros. 

Figura 10 - Mapeamento de hierarquia de valor com sobreposição das percepções de técnicos e
usuários

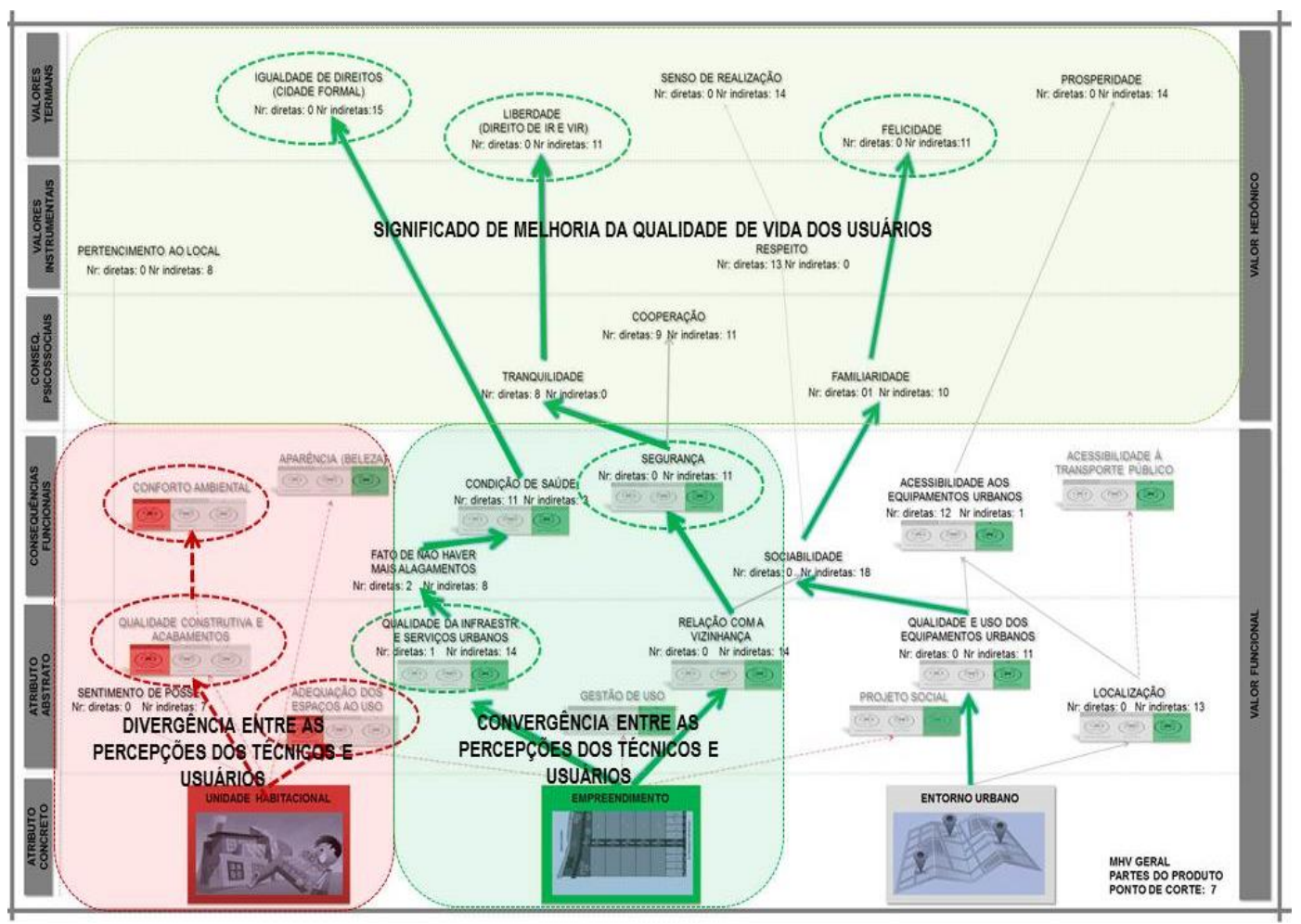

Fonte: Monteiro (2015).

Os resultados desta pesquisa permitiram evidenciar a importância de se avaliar a percepção de valor de ambas as esferas de desenvolvimento e ocupação do produto EHIS. O MHV representando as duas perspectivas de forma combinada, quando apresentado aos técnicos envolvidos no desenvolvimento de EHIS, permitiu que eles conseguissem identificar valores mais abstratos percebidos pelos usuários, insuficientemente explicitados por avaliações até então realizadas (MIRON, 2008; MIRON; FORMOSO, 2009; BONATTO, 2010). O mapeamento a partir da percepção dos usuários demonstrou que não apenas o objetivo apontado pelas pesquisas anteriores e pelos programas habitacionais brasileiros ("melhoria da qualidade de vida") era muito genérico como também indicou de maneira mais explícita como os usuários efetivamente percebem esses valores (ex.: igualdade de direitos, liberdade, felicidade e prosperidade).

Os resultados desta pesquisa também evidenciam que as percepções acerca do produto habitação tendem a ser de natureza complexa. De modo geral, os MHV permitiram explicitar benefícios que eram desejados pelos técnicos e que não foram efetivamente percebidos pelos usuários, principalmente os relacionados à unidade habitacional. Um ponto importante a ser considerado na avaliação é que os benefícios desejados pelos técnicos e não percebidos pelos usuários são os que apresentam os maiores índices de insatisfação. Já os benefícios menos percebidos estão, consequentemente, relacionados aos motivos mais representativos para a saída dos usuários do empreendimento investigado. De modo similar, a avaliação evidenciou que os benefícios desejados pelos técnicos e efetivamente percebidos pelos usuários são os que apresentam os maiores índices de satisfação, estando ainda relacionados às cadeias cognitivas mais representativas no MHV.

Esse resultado sustenta a importância da consideração e aproximação da percepção de técnicos e usuários, uma vez que esta avaliação demonstrou que a convergência entre a percepção desses agentes está diretamente relacionada a resultados mais satisfatórios do produto habitação. Nesse sentido, visando explorar a potencialidade desse tipo de avaliação para a melhoria do produto habitação, futuras pesquisas podem contribuir a partir do refinamento do método (questionário, protocolo de coleta, análise, representação e apresentação de resultados), assim como para a inserção de avaliações no processo de desenvolvimento de outros EHIS brasileiros.

Concluindo, a aproximação entre essas diferentes percepções por meio de hierarquias de valor 
representa uma importante oportunidade para o monitoramento dos resultados dos EHIS. Esse tipo de avaliação possibilita parâmetros comparativos para:

(a) identificar quais benefícios pretendidos (desejados) estão sendo alcançados;

(b) identificar quais benefícios não estão sendo efetivamente atingidos após a ocupação do produto EHIS; e

(c) identificar benefícios importantes que não estão sendo considerados no desenvolvimento dos empreendimentos.

Dessa forma, esse tipo de avaliação pode auxiliar no refinamento do processo de desenvolvimento de EHIS para uma possível maior geração de valor aos usuários, principais beneficiários dos programas habitacionais brasileiros.

\section{Referências}

BONATTO, F. S. Proposta de um modelo para avaliação de empreendimentos habitacionais de interesse social a partir da percepção de clientes finais. Porto Alegre: UFRGS, 2010.

BRITO, J. N. S.; FORMOSO, C. T.; ROCHA, C. S. Estudo da Formação de Valor de Usuários Finais de Empreendimentos Habitacionais de Interesse Social. In: ENCONTRO NACIONAL DE TECNOLOGIA DO AMBIENTE CONSTRUÍDO, 14., Juiz de Fora, 2012. Anais... Juiz de Fora, 2012.

COOLEN, H.; HOEKSTRA, J. Values as Determinants of Preferences for Housing Attributes. Journal of Housing and Built Environment, .v. 16, n. 3/4, p. 285-306, 2001.

GRUNERT, K. G.; GRUNERT, S. C.; SORENSEN, E. Means-End Chains and Laddering: an inventory of problems and an agenda for future research. MAPP working paper 34. Aarhus School of Business, Centre for Market Surveillance, Research and Strategy for the Food Sector, 1995.

GUTMAN, J. A Means-End Chain Model Based on Consumer Categorization Processes. Journal of Marketing, v. 46, p. 60-72, Spring 1982.

GUTMAN, J. Exploring the Nature of Linkages Consequences and Values. Journal of Business Research, v. 22, n. 2, p. 143-48, 1991.

HAIR JUNIOR. J. F. et al. Análise multivariada de dados. 6. ed. Porto Alegre: Bookman, 2009.

JACOBS, J. Morte e Vida das Grandes Cidades. São Paulo: Martin Fontes, 2000.
JUSAN, M. B. M. Means End Chain, Person Environment Congruence and Mass Housing Design. Open House International, v. 35, n. 3, p. 76-86, 2010.

KASANEN, E.; LUKKA, K.; SIITONEN, A. The Constructive Research approach in Management Accounting. Journal of Management Accounting Research, v. 5, p. 243-264, fall 1993.

KHALIFA, A. S. Customer Value: a review of recent literature and an integrative configuration. Management Decision, v. 42, n. 5, p. 645-666, 2004.

LEITE, F. L. Contribuições para o gerenciamento de requisitos do cliente em empreendimentos do Programa de Arrendamento Residencial. Porto Alegre, 2005. 172 f. Dissertação (Mestrado em Engenharia Civil) - Escola de Engenharia, Universidade Federal do Rio Grande do Sul, Porto Alegre, 2005.

LUKKA, K. The Constructive Research. In: OJALA, L.; HILMOLA, O.-P. Case Study Research in Logistics. Turku School of Economics and Business Administration, 2003. Series B1. P. 83-101.

MIRON, L. I. G. Gerenciamento dos Requisitos dos Clientes de Empreendimentos

Habitacionais de Interesse Social: proposto para o Programa Integrado Entrada da Cidade em Porto Alegre/RS. Porto Alegre, 2008. 350 f. Tese (Doutorado em Engenharia Civil) - Escola de Engenharia, Universidade Federal do Rio Grande do Sul, Porto Alegre, 2008.

MIRON, L. I. G.; FORMOSO, C. T. Contribuições Conceituais do Marketing para a Habitação de Interesse Social. In: ENCUENTRO LATINOAMERICANO DE GESTIÓN Y ECONOMÍA DE LA CONSTRUCCIÓN, 3., Bogotá, 2009. Proceedings... Bogotá: Universidad de los Andes, 2009.

MONTEIRO, D. A. B. Proposta de Um Método Para Avaliação da Percepção de Valor em Empreendimentos Habitacionais de Interesse Social. Porto Alegre, 2015. Dissertação (Mestrado em Planejamento Urbano e Regional) - Faculdade de Arquitetura, Universidade Federal do Rio Grande do Sul, Porto Alegre, 2015.

MORAES, L. R. S. et al. Avaliação de Ações Integradas de Saneamento Ambiental e de Moradia em Área Periurbana de Salvador (BA): projeto AISAM III. In: AKIBO, A. K.; ORNSTEIN, S. W. (Eds.). Inserção Urbana e Avaliação PósOcupação (APO) da Habitação de Interesse Social. São Paulo, SP: FAUUSP, 2002. 
PREFEITURA MUNICIPAL DE PORTO

ALEGRE. Entrada da Cidade: Programa Integrado. Porto Alegre: PMPA, 2013. Relatório semestral de acompanhamento da execução física e financeira.

REYNOLDS, T. J.; GUTMAN, J. Laddering Theory, Method, Analysis, and Interpretation. Journal of Advertising Research, v. 28, p. 11-29, 1988.

REYNOLDS, T. J.; GENGLER, C; HOWARD, D. J., A Means-End Analysis of Brand Persuasion Through Advertising. International Journal of Research in Marketing, v. 12, p. 257-266, 1995.

REYNOLDS, T. J.; OLSON, J. C. Understanding Consumer Decision Making: the means-end approach to marketing and advertising strategy. London: Lawrence Erlbaum Associates, 2008.

SILVA, M. N. Percepção de Valor dos Usuários Sobre o Território: estudo de caso no bairro cidade baixa em Porto Alegre - RS. Dissertação (Mestrado em Planejamento Urbano e Regional) Faculdade de Arquitetura, Universidade Federal do Rio Grande do Sul, Porto Alegre, 2014.

TILLMANN, P. et al. Desafios Para a Gestão de Projetos Urbanos Com Elevada Complexidade: análise do Programa Integrado Entrada da Cidade em Porto Alegre, RS. Ambiente Construído, Porto Alegre, v. 11, n. 1, p. 145-158, jan./mar. 2011.
VELUDO-DE-OLIVEIRA, T. M.; IKEDA, A. A Laddering em Pesquisa de Marketing. Cadernos EBAPE.BR, v. 6, n. 5, p. 1-13, 2008.

WOODRUFF, R. B.; GARDIAL, S. F. Know Your Customer: new approaches to understanding customer value and satisfaction. Cambridge: Blackwell Publications, 1996.

ZINAS, B. Z.; BIN, M.; JUSAN, M. M. Choice Behaviour of Housing Attributes: theory and measurement. Asian Journal of EnvironmentBehaviour Studies, v. 1, n. 2, p. 1-18, 2010.

ZINAS, B. Z.; JUSAN, M. M. Motivational Factors Influencing Housing Interior Finish Choice and Preference. Procedia - Social and Behavioral Sciences, v. 36, p. 177-186, 2012.

ZINAS, B. Z. Housing Interior Floor Finishes Choice and Preference and Motivations for Achievement of Person-Environment Congruence. International Journal of Engineering Research and Applications, v. 3, n. 2, p.1404-1412, $2013 \mathrm{a}$.

ZINAS, B. Z. Laddering as a Research Technique For Measuring Housing Choice and Preference. Journal of Environmental Sciences and Resources Management, v. 5, n. 2, 2013b.

\section{Agradecimentos}

Os autores agradecem ao CNPq e à CAPES, à equipe técnica da PMPA e a toda a equipe de preparação, coleta e análise dos dados: Desiree Kuhn; Jose Villamayor; Guilherme Trevisan; Tana Klein e Karin Potter.

Deyvid Aléx de Bitencourt Monteiro

Programa de Pós-Graduação em Planejamento Urbano e Regional | Universidade Federal do Rio Grande do Sul | Rua Sarmento Leite, 320 , $5^{\circ}$ andar | Porto Alegre - RS - Brasil | CEP 90050-170 | Tel.: (51) 3308-3145 | E-mail: deyvidalex@hotmail.com

Luciana Inês Gomes Miron

Programa de Pós-Graduação em Planejamento Urbano e Regional | Universidade Federal do Rio Grande do Sul |

E-mail: luciana.miron@ufrgs.br

\section{Jeferson Shin-Iti Shigaki}

Núcleo Orientado à Inovação da Edificação | Universidade Federal do Rio Grande do Sul | Av. Osvaldo Aranha 99, $3^{\circ}$ andar | Porto Alegre - RS - Brasil | CEP 90035-190 | Tel.: (51) 3308-3518 | E-mail: js_shigaki@yahoo.com.br

\section{Marcia Elisa Soares Echeveste}

Departamento de Estatística | Instituto de Matemática | Universidade Federal do Rio Grande do Sul | Av. Oswaldo Aranha, 99, sala 508, Centro | Porto Alegre - RS - Brasil | CEP 90035-190 | Tel.: (51) 3308-4297 | E-mail: echeveste@producao.ufrgs.br

\section{Revista Ambiente Construído}

Associação Nacional de Tecnologia do Ambiente Construído

Av. Osvaldo Aranha, $99-3^{\circ}$ andar, Centro

Porto Alegre - RS - Brasil CEP $90035-190$

Telefone: +55 (51) 3308-4084

Fax: +55 (51) 3308-4054

www.seer.ufrgs.br/ambienteconstruido

E-mail: ambienteconstruido@ufrgs.br 